\title{
Idosos em Instituições de Longa Permanência: Desenvolvimento, Condições de Vida e Saúde
}

\author{
Elderly in Long-Term Institutions: Development, Living Conditions and Health \\ Júnia Denise Alves-Silva ${ }^{a}$, Fabio Scorsolini-Comin ${ }^{*} a$ \& Manoel Antônio dos Santos ${ }^{b}$ \\ ${ }^{a}$ Universidade Federal do Triângulo Mineiro, Uberaba, Minas Gerais, Brasil \\ $\&{ }^{b}$ Universidade de São Paulo, Ribeirão Preto, São Paulo, Brasil
}

\begin{abstract}
Resumo
O objetivo deste estudo foi realizar uma revisão integrativa da literatura científica a respeito dos fatores que levam os idosos a se transferirem de seu ambiente familiar para instituições de longa permanência para idosos (ILPI), assim como suas condições de vida e saúde. Foram recuperados 14 artigos nas bases SciELO e LILACS (2001-2011). As condições de vida e saúde dos idosos residentes variam entre independência, dependência parcial e dependência total para realização das atividades de vida diária. Ressalta-se a necessidade de mudança na orientação da assistência oferecida a esse grupo, além de aprimoramento na qualificação de cuidadores e trabalho em equipe multiprofissional, a fim de favorecer a qualidade de vida dos idosos que vivem nas ILPI.

Palavras-chave: Envelhecimento, cuidado do idoso, idosos, qualidade de vida.
\end{abstract}

\begin{abstract}
The objective of this study was to conduct an integrative review of the scientific literature about the factors that lead elderly people to transfer from their home environment to long-term care institutions for the elderly (ILPI - in Portuguese) as well as their living conditions and health. For that purpose, 14 articles in SciELO and LILACS (2001-2011) were retrieved. The conditions of life and health of the residents vary between independence, partial dependence and total dependence in performing their daily activities. We stress the need of changing the guidance in the assistance offered as well as improvements in the training of caregivers and multiprofessional groups in order to promote quality of life for the elderly who live in ILPIs.

Keywords: Aging, elderly care, elderly, quality of life.
\end{abstract}

O aumento da população idosa no mundo tem representado uma grande mudança na sociedade moderna (Braz, Del Prette, \& Del Prette, 2011; H. G. Ferreira \& Barham, 2011; Mahieu \& Gastmans, 2012; Morales-Vives \& Vigil-Colet, 2012; Pestana \& Espírito Santo, 2008; Tier, Fontana, \& Soares, 2004). Segundo dados da Organização das Nações Unidas (United Nations [ONU], 2009), há 865 milhões de idosos no mundo, o que corresponde a 12,3\% de toda a população. Estima-se que até 2050 haverá 2,4 bilhões de idosos, ou seja, 26,2\% da população. No Brasil, há cerca de 21 milhões de pessoas com mais de 60 anos, o que corresponde a $11,3 \%$ da população (ONU, 2009). Ainda de acordo com as estimativas, em 2050 haverá cerca de 50 milhões de idosos apenas no Brasil (ONU, 2012). Segundo os dados mais recentes do Instituto Brasileiro de Geografia e Estatística (IBGE, 2011), nos últimos dez

\footnotetext{
" Endereço para correspondência: Departamento de Psicologia, Instituto de Educação, Letras, Artes, Ciências Humanas e Sociais, Universidade Federal do Triângulo Mineiro, Avenida Getúlio Guaritá, 159, Abadia, Uberaba, MG, Brasil 38025-440. E-mail: scorsolini_usp@ yahoo.com.br
}

anos houve um alargamento do topo da pirâmide etária no Brasil, com destaque para o crescimento da participação relativa da população com 65 anos ou mais, que era de $4,8 \%$ em 1991, passando a 5,9\% em 2000 e chegando a $7,4 \%$ em 2010. Também o crescimento absoluto da população brasileira nos últimos dez anos se deu notadamente pelo crescimento da população idosa. Além desses dados populacionais, destaca-se que cerca de 4,5 milhões de idosos terão dificuldades para as atividades da vida diária nos próximos 10 anos, um acréscimo de 1,3 milhão ao contingente observado em 2008 (Camarano \& Mello, 2010). A maior parte desses idosos será do sexo feminino, o que acrescenta a necessidade de discussões mais aprofundadas acerca do gênero nos processos de envelhecimento.

Na perspectiva da Psicologia do Desenvolvimento, o envelhecimento tem sido considerado uma etapa do ciclo vital que tem despertado cada vez mais interesse dos pesquisadores, a despeito do que ocorreu até meados do século XX, em que se priorizavam os processos desenvolvimentais específicos da infância e da adolescência. Atualmente, há um consenso de que na velhice também ocorre o desenvolvimento, caracterizado pelos processos de mudanças, aquisições e perdas (O. G. L. Ferreira, Ma- 
ciel, Silva, Sá, \& Moreira, 2010; Guerra \& Caldas, 2010; Néri, 2001; Sommerhalder, 2010). Nesse sentido, o envelhecimento tem ganhado maior visibilidade e vem sendo considerado um processo natural da vida, permeado por mudanças físicas - como perda de força física, vitalidade e diminuição da coordenação corporal -, psicológicas e sociais (Gonçalves, Vieira, Siqueira, \& Hallal, 2008). Os estudos recentes se preocupam em não apenas identificar as perdas ou os aspectos vitais que declinam com os anos, mas também as novas possibilidades que emergem dessa etapa.

Ao longo do processo de envelhecimento, o ser humano vai se tornando cada vez mais sensível ao meio ambiente devido à diminuição de suas capacidades de adaptação (Rosa, Matsudo, Liposcki, \& Vieira, 2005). É necessário cuidar para que esse processo seja saudável e ativo, o que significa estimular o idoso a praticar sua independência e autocuidado. Caso isso não seja possível, é importante cuidar para que as necessidades do indivíduo sejam supridas, pois o envelhecimento motor do idoso modifica sua interação consigo mesmo, com as outras pessoas e com o mundo (L. R. Ramos, 2003; Rosa et al., 2005).

A família tem uma importância central na vida e na manutenção do bem-estar do idoso, pois pode ser considerada uma fonte de suporte àqueles que necessitam de cuidados. Entretanto, o convívio entre gerações pode gerar conflitos e problemas de relacionamento, que podem se agravar quando os membros da família não são capazes de compreender o comportamento de seus idosos ou quando não conseguem desempenhar a função de cuidadores (Néri et al., 2012). Para aqueles que não encontram respaldo familiar quando necessitam de auxílio para a realização de atividades da vida diária resta a possibilidade de inserção em uma instituição de longa permanência para idosos - ILPI (Tier et al., 2004). Tal inserção também ocorre quando a família não possui estrutura (financeira, emocional, espaço físico, cuidadores), nem conta com o suporte do Estado e de organizações comunitárias para cuidar do familiar idoso no domicílio (Born, 2002, 2008).

As ILPIs têm como objetivo garantir a atenção integral às pessoas com mais de 60 anos, defendendo a sua dignidade os seus direitos. São instituições que buscam prevenir a redução dos riscos aos quais ficam expostos os idosos que não contam com uma moradia (Born, 2008). Essa terminologia é atualmente adotada em substituição ao termo mais consagrado - asilo, que não é apropriado para descrever esses espaços sociais. No entanto, até chegarem a esse estado atual, com legislação específica, diversas discussões foram organizadas entre a sociedade civil, o Estado e as instituições que até então prestavam cuidados aos idosos. As mudanças, nesse sentido, não passam apenas pela nomenclatura, uma vez que o termo asilo carrega sentidos socialmente depreciativos relacionados ao abandono, à pobreza e a condições precárias de saúde e higiene, o que perpassa a construção e a reprodução de mitos, estigmas e estereótipos relacionados a essas instituições, originando diversos preconceitos (Christophe \& Camarano, 2010).
Mais do que isso, as ILPI são uma proposta de uniformização das instituições que prestam assistência aos idosos, garantindo condições de bem-estar físico, emocional e social, em conformidade, entre outros, com o Estatuto do Idoso, com a legislação vigente e com as políticas públicas relacionadas a essa população (Born, 2008; Camarano \& Kanso, 2011). As ILPI surgiram no Brasil na década de 1980 e foram os primeiros locais destinados a cuidar da saúde dos idosos e a suprir suas necessidades básicas, como alimentação e moradia (Pestana \& Espírito Santo, 2008).

A institucionalização do idoso conduz a um distanciamento progressivo da família, às vezes resultando no abandono (Silva, Carvalho, Santos, \& Menezes, 2007). Entretanto, antes de apenas enumerar críticas a esse status $q u o$, é necessário analisar o contexto familiar no qual o idoso estava inserido anteriormente. Em muitos casos, é melhor que eles vivam sob as regras impessoais de uma instituição total do que em casa com a família. Não se pode desconsiderar a importância das instituições de longa permanência para idosos, afinal eles se tornam um lar, um lugar de proteção e cuidado. Observa-se a necessidade de fiscalização desses locais para que sejam cumpridas as normas mínimas exigidas para o funcionamento adequado (Tier et al., 2004).

A ideia, largamente difundida em nosso país, de que as instituições são "depósitos de idosos" foi construída a partir da concepção de que nesses locais há pessoas solitárias e privadas de laços familiares, que ali vivem devido à solidão, ao desprezo e ao abandono. Entretanto, essa percepção vem sendo modificada aos poucos, pois tem sido possível encontrar idosos que se mudam para uma ILPI a partir de uma escolha voluntária, alegando motivos como viuvez, não ter filhos ou não desejar onerar os filhos, preferir ser independente, entre outros motivos (Freitas \& Noronha, 2010). Em geral, o perfil do idoso institucionalizado caracteriza-se pelo aumento do sedentarismo, a perda da autonomia e a ausência de familiares, além das influências de fatores biológicos, doenças e outras causas externas comuns a essa fase de envelhecimento, destacando a ocorrência de quedas como um dos agravos à saúde mais importantes (Gonçalves et al., 2008). O cuidado a idosos institucionalizados vem preocupando a sociedade devido ao crescente aumento da população idosa no Brasil, o que se reflete no aumento da demanda por instituições e das denúncias frequentes que indicam a precariedade de algumas delas (Ribeiro, Ferreira, Magalhães, Moreira, \& Ferreira, 2009).

Os profissionais contratados para cuidar dos idosos e auxiliá-los em suas atividades de vida diária são de fundamental importância na gestão do ambiente das instituições de longa permanência. O Estado deve investir em programas de suporte aos idosos e também aos cuidadores, a fim de garantir a qualidade nos serviços prestados, além de condições de segurança e dignidade aos residentes (Ministério da Saúde, 2003). O aumento dos salários de funcionários, de aposentadorias e também o apoio em 
áreas de suma importância como alimentação, transporte e assistência médica são algumas medidas que propiciariam um atendimento adequado às necessidades dos idosos (Camarano \& Kanso, 2010; Chaimowicz, 1997). O apoio e incentivo a uma formação continuada podem contribuir para o desenvolvimento dos profissionais envolvidos na atenção aos idosos nesse contexto, promovendo práticas mais adequadas e reflexões que convidem para a implementação de transformações nesse cenário (Lenardt et al., 2006; Reis \& Ceolim, 2007; Silva et al., 2007).

Devido a essas questões abordadas, denota-se a necessidade de mapear os estudos disponíveis sobre os idosos, com vistas a delinear o estado da arte dos problemas emergentes. Uma das dimensões mais relevantes para a compreensão do fenômeno da inserção do idoso no contexto institucional diz respeito aos motivos que deflagram a busca das ILPI. Nessa direção, a pergunta de pesquisa que delineou o presente estudo foi: qual o estado atual do conhecimento acumulado nessa área? Ou seja, o que se sabe sobre as razões que impelem um idoso a se mudar para uma instituição de longa permanência e quais são suas condições de vida enquanto residente?

Em busca dessa compreensão, o objetivo deste estudo foi realizar uma revisão crítica da literatura científica nacional a respeito dos fatores que levam um idoso a se encaminhar para uma instituição de longa permanência, ao invés de se manter em seu ambiente familiar. Também se objetivou analisar o conhecimento disponível acerca da situação de saúde e das condições de vida enfrentadas pelo idoso residente na ILPI.

\section{Método}

Trata-se de um estudo de revisão sistemática da literatura, na modalidade integrativa, que busca sumarizar resultados de pesquisas consolidadas e tirar conclusões globais a partir de um corpo de literatura de um tópico em particular, de modo a contribuir para discussões sobre métodos e resultados de pesquisa, assim como proporcionar reflexões que subsidiem a realização de futuras investigações. Seguindo procedimentos específicos, como o estabelecimento de critérios de inclusão e exclusão dos estudos e análise crítica dos resultados, observa-se que, embora os métodos para a condução de revisões integrativas variem, existem padrões a serem seguidos, como o rigor e clareza na revisão. A revisão de literatura possui tanto uma dimensão de categorização, de caráter descritivo, como uma faceta de análise crítica, ou seja, que ultrapassa a simples explicitação daquilo que já se produziu, possibilitando uma leitura atenta da realidade que aponta lacunas e necessidades de investigação ainda não suficientemente contempladas pelos pesquisadores (Creswell, 2010).

A prática baseada em evidências é uma abordagem que permite o desenvolvimento e/ou utilização de resultados de pesquisas nas intervenções práticas. Como os pesquisadores na área de saúde deparam-se com a quantidade e complexidade de informações na área, abre-se a necessidade de métodos de revisão como o apresentado no presente estudo. Assim, a revisão integrativa é um método de pesquisa que permite a busca, a avaliação crítica e a síntese das evidências disponíveis do tema investigado, sendo o seu produto final o estado atual do conhecimento do tema, abrindo a possibilidade de intervenções efetivas na assistência à saúde e a redução de custos (Mendes, Silveira, \& Galvão, 2008).

Assim, o objetivo do estudo foi apresentar os conceitos gerais e as etapas para a elaboração da revisão integrativa, bem como aspectos relevantes sobre a aplicabilidade deste método para a pesquisa na saúde. Os critérios de inclusão foram: artigos indexados disponíveis nas bases LILACS e SciELO, no período de 2001 a 2011. Os descritores utilizados foram "instituição de longa permanência para idosos" e "asilo para idosos". Teses, dissertações, livros, capítulos de livros, resenhas, cartas e notícias foram excluídos, assim como os artigos que não correspondiam diretamente ao tema de interesse. Após a seleção dos artigos, observou-se a repetição de alguns. Foram excluídos aqueles que anteriormente haviam sido encontrados na mesma base de dados, mas com um descritor diferente. Isso ocorreu também entre as duas bases quando o mesmo artigo foi selecionado em ambas. Portanto, para fins de contabilização do número de publicações selecionadas, artigos repetidos foram computados uma única vez. Após a leitura de todos os resumos, foram aplicados os critérios de inclusão/exclusão para recuperação dos trabalhos. Realizado esse processo, foram lidos os artigos selecionados na íntegra. A partir dessa leitura, foram excluídos os artigos que se mostraram distantes da temática investigada. Desse modo, os artigos recuperados nesta última seleção foram analisados em profundidade, sendo agrupados em eixos temáticos que emergiram a partir da leitura de seus conteúdos.

\section{Resultados e Discussão}

Na base de dados SciELO foi encontrado um total de 38 artigos, sendo 24 a partir do descritor "instituição de longa permanência para idosos" e 14 com o uso do descritor "asilo para idosos". Já na base de dados LILACS foi encontrado um total de 356 trabalhos, sendo 303 a partir do descritor "instituição de longa permanência para idosos" e 53 com o uso do descritor "asilo para idosos". A maior parte dos estudos excluídos deveu-se ao fato de serem capítulos ou livros sobre idosos (a maior parte recuperada a partir do LILACS) ou por apenas mencionarem as ILPI, não desenvolvendo uma investigação com foco nessas instituições. Ao final, foram recuperados e analisados 14 estudos. A Tabela 1 apresenta a identificação dos artigos selecionados nesta revisão. A variável país de origem não foi utilizada porque todos os artigos foram escritos no idioma português e publicados em revistas brasileiras.

A Tabela 2 apresenta uma síntese dos objetivos dos 14 artigos recuperados. 
Alves-Silva, J. D., Scorsolini-Comin, F. \& Santos, M. A. (2013). Idosos em Instituições de Longa Permanência: Desenvolvimento, Condições de Vida e Saúde.

Tabela 1

Identificação dos Artigos Recuperados e Analisados em Termos dos Títulos, Autores, Ano da Publicação e Periódico

\begin{tabular}{|c|c|c|c|c|}
\hline $\mathrm{N}^{\circ}$ do artigo & Título & Autor(es) & Ano & Periódico \\
\hline 1 & $\begin{array}{l}\text { Os idosos e as instituições asilares } \\
\text { do município de Campinas }\end{array}$ & Yamamoto \& Diogo & 2002 & $\begin{array}{l}\text { Revista Latino-Americana } \\
\text { de Enfermagem }\end{array}$ \\
\hline 2 & $\begin{array}{l}\text { Estudos com idosos de instituições } \\
\text { asilares no município de Natal/RN: } \\
\text { Características socioeconômicas } \\
\text { e de saúde }\end{array}$ & $\begin{array}{l}\text { Davim, Torres, } \\
\text { Dantas, \& Lima }\end{array}$ & 2004 & $\begin{array}{l}\text { Revista Latino-Americana } \\
\text { de Enfermagem }\end{array}$ \\
\hline 3 & $\begin{array}{l}\text { “E agora... de quem cuidarei?”. } \\
\text { O cuidar na percepção de idosas } \\
\text { institucionalizadas } \\
\text { e não institucionalizadas }\end{array}$ & Duarte \& Santos & 2004 & $\begin{array}{l}\text { Psicologia: Ciência e } \\
\text { Profissão }\end{array}$ \\
\hline 4 & $\begin{array}{l}\text { A saúde sob o olhar do idoso } \\
\text { institucionalizado: Conhecendo } \\
\text { e valorizando sua opinião }\end{array}$ & Freire \& Tavares & 2005 & $\begin{array}{l}\text { Interface: Comunicação, } \\
\text { Saúde, Educação }\end{array}$ \\
\hline 5 & $\begin{array}{l}\text { Avaliação do grau de independência } \\
\text { de idosos residentes em instituições } \\
\text { de longa permanência }\end{array}$ & $\begin{array}{l}\text { M. O. P. H. Araújo } \\
\text { \& Ceolim }\end{array}$ & 2007 & $\begin{array}{l}\text { Revista da Escola de } \\
\text { Enfermagem da USP }\end{array}$ \\
\hline 6 & $\begin{array}{l}\text { Em busca de uma instituição para a } \\
\text { pessoa idosa morar: Motivos apontados } \\
\text { por familiares }\end{array}$ & $\begin{array}{l}\text { Perlini, Leite, } \\
\text { \& Furini }\end{array}$ & 2007 & $\begin{array}{l}\text { Revista da Escola de } \\
\text { Enfermagem da USP }\end{array}$ \\
\hline 7 & $\begin{array}{l}\text { Prevalência de sintomas depressivos } \\
\text { em idosos institucionalizados na cidade } \\
\text { de Salvador }\end{array}$ & Santana \& Barboza & 2007 & $\begin{array}{l}\text { Revista Baiana de Saúde } \\
\text { Pública }\end{array}$ \\
\hline 8 & $\begin{array}{l}\text { Aspectos sociodemográficos, de } \\
\text { saúde e nível de satisfação de idosos } \\
\text { institucionalizados no Distrito Federal }\end{array}$ & N. P. Araújo et al. & 2008 & $\begin{array}{l}\text { Revista de Ciências } \\
\text { Médicas }\end{array}$ \\
\hline 9 & $\begin{array}{l}\text { Motivações para o ingresso dos idosos } \\
\text { em instituições de longa permanência } \\
\text { e processos adaptativos: Um estudo } \\
\text { de caso }\end{array}$ & Bessa \& Silva & 2008 & $\begin{array}{l}\text { Revista Texto \& Contexto } \\
\text { Enfermagem }\end{array}$ \\
\hline 10 & $\begin{array}{l}\text { Mulheres idosas enfrentando a } \\
\text { institucionalização }\end{array}$ & $\begin{array}{l}\text { Pavan, Meneghel, } \\
\text { \& Junges }\end{array}$ & 2008 & $\begin{array}{l}\text { Cadernos de Saúde } \\
\text { Pública }\end{array}$ \\
\hline 11 & $\begin{array}{l}\text { Idosos em uma Instituição de Longa } \\
\text { Permanência de Ribeirão Preto: Niveis } \\
\text { de capacidade funcional }\end{array}$ & $\begin{array}{l}\text { Pelegrin, Araújo, } \\
\text { Costa, Cyrillo, } \\
\text { \& Rosset }\end{array}$ & 2008 & $\begin{array}{l}\text { Revista Arquivos de } \\
\text { Ciências da Saúde }\end{array}$ \\
\hline 12 & $\begin{array}{l}\text { Situação de saúde e grau de dependência } \\
\text { de pessoas idosas institucionalizadas }\end{array}$ & Aires, Paz, \& Perosa & 2009 & $\begin{array}{l}\text { Revista Gaúcha de } \\
\text { Enfermagem }\end{array}$ \\
\hline 13 & $\begin{array}{l}\text { Qualidade de sono de idosos residentes } \\
\text { em instituição de longa permanência }\end{array}$ & $\begin{array}{l}\text { C. L. O. Araújo } \\
\text { \& Ceolim }\end{array}$ & 2010 & $\begin{array}{l}\text { Revista da Escola de } \\
\text { Enfermagem da USP }\end{array}$ \\
\hline 14 & $\begin{array}{l}\text { Avaliação da qualidade de vida em } \\
\text { idosos institucionalizados no município }\end{array}$ & $\begin{array}{l}\text { Nunes, Menezes, } \\
\text { \& Alchieri }\end{array}$ & 2010 & $\begin{array}{l}\text { Acta Scientiarum, Health } \\
\text { Sciences }\end{array}$ \\
\hline
\end{tabular}


Tabela 2

Objetivos dos Artigos Recuperados

\begin{tabular}{ll}
$\mathrm{N}^{\mathrm{o}}$ do artigo & Objetivos \\
\hline
\end{tabular}

1 Caracterizar as instituições asilares da cidade de Campinas (SP) quanto aos seus residentes, recursos humanos e rotinas institucionalizadas

2 Caracterizar o idoso asilado e identificar os problemas socioeconômicos, de saúde e as causas que os levaram à instituição

3 Investigar a percepção de idosas (institucionalizadas e não-institucionalizadas) sobre o cuidado consigo e com o outro, comparando-a com suas necessidades atuais de cuidados

4 Analisar as percepções que o idoso do Lar dos Idosos Monsenhor Rocha (Caratinga, MG) tem de sua saúde nesta etapa da vida

5 Identificar o grau de independência para a realização de atividades da vida diária (AVDs) dos idosos residentes nas instituições da cidade de Taubaté (SP)

6 Conhecer as situações que motivam famílias a asilar seu familiar idoso

7 Estimar a prevalência de sintomas depressivos em idosos institucionalizados e as variáveis associadas a este evento

8 Explorar os aspectos sociodemográficos e de saúde de idosos institucionalizados no Distrito Federal e seu nível de satisfação com a instituição

9 Conhecer os principais fatores que levam um idoso a procurar uma Instituição de Longa Permanência e de que maneira se dá sua adaptação a esse ambiente

10 Entender como a mulher idosa percebe a institucionalização, quais os efeitos decorrentes de gênero e de que maneira essas idosas enfrentam o envelhecimento nessa situação

11 Identificar os níveis de capacidade funcional de idosos em uma instituição de longa permanência de Ribeirão Preto (SP). Avaliar o nível de dependência para a realização das Atividades da Vida Diária. Identificar o perfil sociodemográfico e a presença de doenças crônicas. Conhecer os medicamentos utilizados pelos idosos e os profissionais que prestam cuidados a eles, bem como o perfil da instituição

12 Identificar as características demográficas, socioeconômicas, comportamentais, situação de saúde e grau de dependência de idosos institucionalizados

13 Avaliar a qualidade do sono de idosos residentes em quatro instituições de longa permanência para idosos de uma cidade do interior do Estado de São Paulo e identificar problemas relacionados ao sono

14 Avaliar a qualidade de vida $(\mathrm{QV})$ de idosos residentes em instituições de longa permanência a partir da identificação dos aspectos sociodemográficos que os envolvem, das atividades inerentes à saúde e à sua institucionalização, além dos aspectos relacionados com a QV, considerados relevantes para os idosos

Os artigos revisados tiveram seus conteúdos categorizados. A seguir, serão apresentados e discutidos os eixos de análise.

\section{Perfil dos Idosos Institucionalizados}

O estudo realizado por O. G. L. Ferreira et al. (2010) com 100 idosos funcionalmente independentes da cidade de João Pessoa (PB) mostrou que a representação do envelhecimento baseou-se em aspectos negativos, ao associar esse processo a ideias como limitação, inutilidade e doença. Quando associado à palavra "ativo", o envelhecimento apresentou aspectos mais positivos, tais como independência, alegria e trabalho. Essa visão negativa é muito influenciada pelas referências pessoais e culturais dos indivíduos que vivem em uma sociedade centrada na juventude, produção e rendimento. A velhice apresenta-se negativamente nesse contexto social, contribuindo para a identificação da imagem do idoso com fracasso, doença e sofrimento, o que culmina na sua exclusão (Guerra \& Caldas, 2010). 
Conforme observado em pesquisas realizadas em algumas cidades dos estados de São Paulo, Rio Grande do Norte, Rio Grande do Sul e Distrito Federal (Aires et al., 2009; M. O. P. H. Araújo \& Ceolim, 2007; N. P. Araújo et al., 2008; Davim et al., 2004; Duarte \& Santos, 2004; Nunes et al., 2010; Pavan et al., 2008; Yamamoto \& Diogo, 2002) há um predomínio do sexo feminino entre os residentes nas instituições de longa permanência. Esses dados estão em concordância com a distribuição proporcional dos sexos por idade. A tendência mundial indica que a diferença entre homens e mulheres se acentua com o envelhecimento porque, geralmente, os homens morrem mais cedo do que as mulheres. Muitos, aliás, morrem quando ainda são jovens devido à maior exposição a riscos. Esse fato complementa a ideia da maior probabilidade de as mulheres ficarem viúvas e em situação econômica desvantajosa, levando-as mais frequentemente à institucionalização. A exceção encontrada foi a pesquisa realizada na cidade de Ribeirão Preto - SP (Pelegrin et al., 2008) que encontrou um predomínio de idosos do sexo masculino, pouco mais de $50 \%$ do total.

O baixo nível de escolaridade foi outro quesito amplamente verificado em todas as pesquisas. Isso pode ser explicado pela pouca valorização que o estudo tinha na época da infância desses idosos. A educação não era prioridade, principalmente para as mulheres, o que reflete no baixo índice de instrução encontrado entre os idosos institucionalizados. Além disso, a maioria dos entrevistados nas diversas pesquisas havia realizado trabalhos braçais e pouco remunerados. Seu sustento se dá por meio da aposentadoria, quase sempre integralmente repassada à instituição no qual estão inseridos.

Deve-se ressaltar a importância de os profissionais das instituições adaptarem suas atividades às condições dos idosos residentes, sem desconsiderar essa questão da baixa escolaridade e de alterações do envelhecimento, como diminuição da acuidade visual e auditiva. Conforme discutido no artigo de N. P. Araújo et al. (2008), a adaptação das atividades propostas e da linguagem aos idosos propicia o entendimento do significado e da importância das informações, a fim de que elas sejam realizadas satisfatoriamente. Observou-se também uma alta porcentagem de idosos solteiros. Ainda segundo o mesmo artigo, a ausência de vínculos familiares pode transformar o cuidado com o idoso em tarefa difícil, o que pode ser fator desencadeador de sua institucionalização. No campo das doenças, as condições crônicas são predominantes.

Quanto à autonomia e independência, os idosos podem ser subdivididos em três níveis: independentes, parcialmente dependentes (ou semidependentes) e totalmente dependentes. Conforme discutido por M. O. P. H. Araújo e Ceolim (2007), à medida que o ser humano envelhece, tarefas cotidianas consideradas de fácil execução (como alimentar-se, locomover-se e tomar banho) vão se tornando cada vez mais difíceis de serem realizadas, até que o indivíduo se perceba dependente de outra pessoa para executá-las. No artigo de Aires et al. (2009), observou-se uma maior dependência dos idosos para tomar banho. Para tanto, os cuidadores da instituição relatam que tomam cuidado redobrado durante essa atividade a fim de evitar a ocorrência de quedas. Nesse sentido, apresenta-se a necessidade de discutir, no contexto das ILPI, como pode ser promovida a autonomia dos idosos para as atividades da vida diária, como já pontuado por Camarano e Mello (2010)

Conforme discutido por Rosa et al. (2005), a percepção do eu vai se modificando à medida que o ser humano se desenvolve, sendo o ambiente grande influenciador da imagem que o indivíduo constrói de si mesmo, ou seja, sua autoimagem. Se a sociedade considera a pessoa idosa como menos capaz, é natural que o indivíduo nessa fase interiorize essa ideia à medida que percebe seu vigor e sua força declinarem. A institucionalização do idoso pode representar uma ruptura de um status anterior, o que pode colocá-lo em uma situação de isolamento social. A diminuição das capacidades visual, auditiva, cognitiva e física do idoso muitas vezes compromete sua autonomia e independência, refletindo significativamente em sua qualidade de vida. Isso pode ser comprovado pelo artigo de Nunes et al. (2010), que encontrou a perda da autonomia como fator mais relatado pelos idosos como causador de insatisfação, o que indica a valorização da capacidade de autocuidado e do bom desempenho na realização das atividades de vida diária. Deve-se ressaltar que, muitas vezes, a dependência é estimulada pelos próprios funcionários nos ambientes das ILPI, que preferem cumprir a atividade para o idoso ao invés de esperá-lo concluí-la. Uma questão levantada pelo artigo de M. O. P. H. Araújo e Ceolim (2007) é que mesmo um idoso independente, quando institucionalizado, pode desenvolver certos graus de dependência devido à sua dificuldade em aceitar e adaptar-se às novas condições de vida que tem que enfrentar. É preciso estimular esses idosos independentes para que se mantenham nessa condição, favorecendo a autonomia.

\section{Como o Idoso Compreende sua Saúde}

De acordo com a definição proposta pela VIII Conferência Nacional de Saúde, realizada em 1986, a saúde é um conceito que extrapola os aspectos biológicos e com foco na ausência de doenças. Advoga-se uma noção mais ampliada e dinâmica, de saúde como produto social resultante da ação de diversos determinantes materiais, entre eles o acesso à educação, moradia, lazer, trabalho, serviços de saúde, entre outros (Conferência Nacional de Saúde, 1986). Segundo o artigo de Freire e Tavares (2005), os idosos entrevistados denotaram compreensão desse conceito ao destacarem, além da ausência de dor, a ligação entre capacidade funcional, autonomia, independência e o fato de poderem trabalhar.

É muito importante que o idoso compreenda o que se passa em relação à própria saúde, de modo que desenvolva um processo de empoderamento que o torne capaz de se 
cuidar. Conforme discutido por Freire e Tavares (2005), a velhice é marcada pela aposentadoria e pela desqualificação do idoso como mão de obra para o mercado de trabalho, o que se reflete negativamente em seu estado de saúde por ser uma situação contrária ao processo de empoderamento.

Muitos idosos encaram a institucionalização como perda da liberdade, abandono e aproximação inexorável da morte. Apesar disso, não se pode esquecer que a ILPI cumpre o papel de oferecer abrigo aos idosos, podendo se converter no único ponto de referência para eles. $\mathrm{O}$ idoso institucionalizado encontra-se afastado da família, dos amigos e das relações nas quais sua história de vida foi construída. As redes de apoio e convívio construídas no âmbito institucional funcionam como estratégias eficientes de enfrentamento das situações difíceis, pois, conforme discutido por Brandão, Smith, Sperb e Parente (2006) e Duarte e Santos (2004), os idosos apresentam uma tendência natural para se tornarem contadores de histórias, visto que as narrativas pessoais marcam suas falas, frequentemente repletas de lembranças do passado.

Carneiro, Falcone, Clark, Del Prette e Del Prette (2007) discutem a importância dos relacionamentos sociais para a preservação do bem-estar físico e mental do idoso e para a apreciação de sua qualidade de vida, baseando-se nos argumentos de diversos estudos (M. P. Ramos, 2002; Silberman et al., 1995) que reforçam a ideia de que as relações sociais podem promover melhores condições de vida. A ausência de convívio social seria também um fator de risco à saúde, o que sugere que a deterioração da situação de saúde pode ser causada também pela redução da quantidade ou qualidade das relações sociais.

\section{Qualidade do Sono e Depressão na Terceira Idade}

A má qualidade do sono tem relevância entre os idosos, visto que pode causar prejuízos ao cotidiano e à saúde. De acordo com o estudo de C. L. O. Araújo e Ceolim (2010), a deterioração da qualidade do sono de idosos institucionalizados é atribuída ao ambiente e às rotinas da ILPI. As noites são marcadas pela fragmentação do sono, com despertares frequentes que podem produzir sonolência diurna excessiva. Os distúrbios destacados na pesquisa foram: levantar-se para ir ao banheiro, acordar no meio da noite ou de manhã muito cedo, sentir muito calor, sentir dores, tossir ou roncar alto e ter sonhos ruins ou pesadelos. Mais de $60 \%$ dos idosos entrevistados apresentaram pontuação indicativa de má qualidade de sono. Entretanto, 81,6\% referiram qualidade de sono boa ou muito boa quando indagados sobre a mesma. Não se pode concluir o porquê dessa discrepância. O idoso pode estar realmente satisfeito com sua qualidade de sono ou então se acostumou a ter um sono pouco satisfatório, acreditando que isso é normal para a sua idade, segundo possibilidades levantadas pelos autores do artigo. É preciso que novos estudos aprofundem a investigação a respeito dessa temática.

Quanto à depressão, juntamente com as síndromes demenciais representam os transtornos psiquiátricos mais prevalentes em indivíduos da terceira idade. O processo de institucionalização constitui-se de uma situação estressante e potencialmente desencadeadora de quadros de depressão. De acordo com o artigo de Santana e Barboza (2007), o idoso se vê isolado de seu convívio social e tem de se adaptar a um estilo de vida diferente do seu, com a adoção de uma rotina de horários, compartilhamento do ambiente e de sua intimidade com desconhecidos, além da distância da família. Tudo isso pode ocasionar a perda da liberdade e da autoestima do idoso, justificando a alta prevalência de depressão em ILPI.

Conforme discutido por Davim et al. (2004), o idoso tem sido visto como uma pessoa improdutiva e pouco tem sido feito para mudar essa representação social. As instituições acabam por favorecer o isolamento do idoso ao dificultar suas relações interpessoais no contexto comunitário e reforçar sua inatividade física e mental, o que reflete negativamente em sua qualidade de vida. $\mathrm{O}$ interesse pelos outros tende a diminuir no idoso, que se interessa mais por si próprio e fica mais isolado. Durante a realização da coleta de dados, os autores observaram várias idosas nos corredores da instituição da cidade de Fortaleza (CE), mas que não conversavam entre si. Além disso, não é comum a presença de uma idosa no quarto da outra, o que acontece somente mediante convite. Desse modo, é possível que a tendência ao isolamento esteja relacionada à solidão do idoso e às alterações observadas em seu contexto familiar, principalmente a escassez de contatos ou perdas de familiares.

\section{Perfil das Instituições de Longa Permanência}

Em geral, as instituições de longa permanência apresentam um poder disciplinar e são marcadas por regras rígidas e rotina diária regida por horários determinados. Devido à vida padronizada e à falta de perspectiva, os idosos perdem o direito de expressar sua subjetividade e seus desejos, vendo sua vida limitada social, afetiva e sexualmente em um espaço físico semelhante a grandes alojamentos, onde raramente se encontra uma proposta de trabalho voltada para a manutenção de idosos independentes e autônomos. Segundo o estudo de Pavan et al. (2008), o tão sonhado tempo livre no ambiente da instituição acaba por se tornar um tempo vazio de significado, convertendo-se na experiência desoladora da espera pela morte. Isso demonstra que o idoso tem sido encarado como uma pessoa improdutiva e que pouco tem sido feito para mudar essa situação.

De acordo com o artigo de Yamamoto e Diogo (2002), o novo perfil da população brasileira exigirá profissionais especializados na área gerontológica e geriátrica, a fim de atender à demanda crescente por esses serviços. Ressalta-se, também, a necessidade de que as instituições destinadas ao cuidado de idosos contem com pessoas qualificadas para tal assistência, visando atender às necessidades peculiares dos idosos, principalmente daqueles mais fragilizados e dependentes. 
Para que uma instituição geriátrica mantenha-se em funcionamento adequado, deve cumprir padrões mínimos exigidos, como horas semanais de assistência médica, de enfermagem, assistência psicossocial, nutricional, de reabilitação, entre outros. Apesar dessas condições estarem claramente definidas em termos legais, observa-se a inexistência de equipes multiprofissionais no âmbito das instituições. Foram encontrados, principalmente, profissionais pouco qualificados para exercer as atividades sob sua responsabilidade, denominados, por isso, de cuidadores. Trentini, Chachamovich, Figueiredo, Hirakata e Fleck (2006) destacam a tendência que o cuidador tem de perceber a qualidade de vida do idoso como inferior à própria percepção do idoso, considerando-os mais frágeis e lamentando o estado que observam de fora.

É importante observar que os principais cuidados oferecidos pelas instituições são os providos por médicos e enfermeiros. Há um enfoque na busca de solução de problemas, como a cura das doenças, o que sugere um predomínio do modelo curativista em detrimento do cuidado integral à saúde do idoso. De acordo com Garbin, Sumida, Moimaz, Prado e Silva (2010), a saúde mental interfere na saúde geral do idoso, visto que, mesmo apresentando todas as condições de ter uma vida saudável e segura, ele não tem ânimo para desfrutar de nada se não encontrar em seu ambiente carinho, diversão, emoção e alegria. As situações crônicas de tristeza, solidão e abandono impedem que os idosos tenham ânimo para aproveitar a vida.

\section{Motivações para a Institucionalização do Idoso}

Segundo o estudo de Perlini et al. (2007), as famílias tendem a buscar um ambiente que se revele melhor ao idoso do que o ambiente familiar, ou seja, um local que ofereça cuidados, companhia e convivência com outros idosos. Apesar dessa ideia, as pesquisas apontaram motivos variados para justificar a institucionalização do idoso. As mudanças na estrutura familiar e social transformam também as formas de vínculos e de relações intergeracionais, que podem comprometer as funções de proteger e cuidar do idoso dependente para a realização das atividades de vida diária. Os conflitos em família podem fazer com que o idoso se encaminhe para uma instituição de longa permanência, passando a ter esse local como referência de um ambiente familiar. Há também os conflitos mobilizados entre membros da família originados pela postura intransigente e autoritária do idoso (Perlini et al., 2007). Isso é possível de se compreender, pois o idoso tem suas experiências de vida, seus costumes e hábitos arraigados. Idosos desprovidos de família nuclear também apresentam maior probabilidade de institucionalização. A perda progressiva de entes significativos pode levar o idoso a procurar espaços onde possam ser acolhidos.

As visitas são consideradas mantenedoras do vínculo familiar. Na cidade de Ijuí (RS), observou-se que os idosos recebiam mais visitas de pessoas de seu núcleo familiar, mas que, com o passar do tempo, essa frequência decrescia
(Perlini et al., 2007). Isso resultava na fragilidade dos laços familiares, o que levava, gradativamente, ao agravamento do esquecimento do idoso. No bojo dessas discussões, deve-se ressaltar que, em termos dos cuidados oferecidos aos idosos, Camarano e Kanso (2010) salientam a premência de se abordar a tríade família-instituições-Estado no sentido de prover serviços de cuidados para a população dependente. Ainda, autores propõem uma desconstrução do conceito de família como uma instituição idealizada e com um único perfil, o que pode contribuir para que a assistência ao idoso não busque por uma família "ideal", mas pela "concreta" e "possível" (Néri et al., 2012). Outro ponto a ser amplamente discutido refere-se ao fato de que o idoso institucionalizado não deve ser compreendido como alguém que não foi cuidado ou que não teve outras oportunidades de inserção e de apoio. As ILPI visam a uma oferta de cuidados que ultrapassam a visão assistencialista, privilegiando a assunção de posturas que efetivamente compreendam os idosos como cidadãos.

\section{Por uma Institucionalização mais Humanizada}

Um idoso institucionalizado é uma pessoa em condição de desfrutar dos direitos básicos de cidadania. Os estudos sugerem que é fundamental a adequação e reorganização dos serviços oferecidos nas ILPI, a fim de corresponderem à crescente demanda da população brasileira que envelhece e necessita de cuidados, além de favorecer o desempenho de atividades prazerosas ao idoso nesses cenários. $\mathrm{O}$ modelo vigente da institucionalização do idoso é marcado por casos de depressão, confusão mental, perda de contato com a realidade, isolamento, resignação e acomodação passiva à situação de desamparo. Segundo o estudo de Davim et al. (2004), as instituições não devem se configurar apenas como locais que acolhem idosos abandonados pela família, mas também devem ser compreendidos como uma escolha dentro de um contexto de vida.

Visto que a população brasileira tende a apresentar um número cada vez maior de idosos, destaca-se a necessidade de rever as políticas nacionais referentes a esse grupo. Além disso, a perspectiva de gênero deve ser discutida com mais afinco, haja vista o predomínio de mulheres nessa faixa etária, o que, por si só, enleva a necessidade de políticas específicas de saúde e de desenvolvimento (Camarano \& Mello, 2010). Compreende-se que a institucionalização pode ser mais humanizada e funcionar de forma menos rígida, a fim de que esses locais percam o estereótipo de sombrios depósitos de velhos. Independentemente dos motivos que levaram o idoso a encaminhar-se a uma instituição, permanecem intactos os seus direitos de cidadania.

\section{Considerações Finais}

Por meio do presente estudo, pode-se perceber que os fatores que levam um idoso a se transferir de seu ambiente familiar para uma instituição de longa permanência são 
variados, desde por escolha própria até por imposição da família. As condições de vida e saúde desses idosos, então residentes das ILPI, variam entre a independência, dependência parcial e dependência total para a realização das atividades de vida diária. Grande parte dos idosos entrevistados nos estudos aqui resgatados apresenta algum tipo de dependência, o que sugere a necessidade do auxílio de um cuidador ou profissional. No entanto, um ponto a ser discutido de modo crítico é a busca pela autonomia dos idosos, o que pode ser fomentado nas ILPI como uma política de promoção da saúde. Quanto às rotinas, a literatura revela que as ILPI mostram-se como lugares monótonos e que não propiciam ao idoso a realização de atividades que possibilitem novas experiências, a partir do contato com os demais residentes, assim como a valorização das antigas vivências e habilidades adquiridas, o que pressupõe o envelhecimento como uma etapa na qual não mais ocorre o desenvolvimento ou o aprendizado. No entanto, pesquisadores contemporâneos têm salientado a necessidade de desconstrução das ILPI como meras derivações das instituições asilares (sobre as quais pesam estigmas e preconceitos), promovendo leituras críticas que possibilitem a construção de uma noção de ILPI que justamente seja um espaço privilegiado de desenvolvimento para os idosos, cotejando as principais políticas públicas relacionadas a essa população e em vigência no Brasil. Para além de uma visão focada na assistência a um sujeito que necessita de cuidados, as ILPI devem ser reconhecidas também como espaços promotores de desenvolvimento, aprendizado e saúde. Como um ambiente que visa a promover desenvolvimento, mudanças podem ser elencadas no sentido de favorecer a adaptação dos idosos, primando-se não pelo caráter assistencialista associado às ILPI, mas pelas diversas possibilidades que podem ser recuperadas no contato com os idosos: o que eles têm a compartilhar? $\mathrm{O}$ que eles podem nos ensinar? De que modo eles ainda podem se transformar e aprender? Essas são questões essenciais que podem nortear novas propostas de organização desses espaços coletivos.

A maioria dos artigos foi extraída de revistas de Enfermagem. Isso sugere um interesse específico pelas questões relativas à institucionalização do idoso. Esse interesse pode estar relacionado ao fato de que o enfermeiro é o profissional mais próximo ao idoso e tem presença contínua dentro das ILPI e, por isso, tem mais condições de acompanhar o ritmo de vida desse grupo e eleger esse campo para desenvolver pesquisas. $\mathrm{O}$ aumento do número e da qualificação de cuidadores profissionais e a efetivação do que preconizam as políticas públicas no que concerne à formação de equipes multiprofissionais para atuarem nas instituições, são medidas que poderiam enriquecer o cotidiano dos idosos residentes. Nesse sentido, a revisão integrativa, em uma perspectiva baseada em evidências, aponta para possíveis caminhos no que tange às intervenções que podem ser implementadas em ILPI por diferentes saberes profissionais em saúde.

\section{Referências}

Aires, M., Paz, A. A., \& Perosa, C. T. (2009). Situação de saúde e grau de dependência de pessoas idosas institucionalizadas. Revista Gaúcha de Enfermagem, 30(3), 492-499.

Araújo, C. L. O., \& Ceolim, M. F. (2010). Qualidade do sono de idosos residentes em instituição de longa permanência Revista da Escola de Enfermagem da USP, 44(3), 619-626.

Araújo, M. O. P. H., \& Ceolim, M. F. (2007). Avaliação do grau de independência de idosos residentes em instituições de longa permanência. Revista da Escola de Enfermagem da USP, 41(3), 378-385.

Araújo, N. P., Britto, D. C. C., Santos, F. L., Filho, Costa, R. V., Zoccoli, T. L. V., \& Novaes, M. R. C. G. (2008). Aspectos sociodemográficos, de saúde e nível de satisfação de idosos institucionalizados no Distrito Federal. Revista de Ciências Médicas, 17(3-6), 123-132.

Bessa, M. E. P., \& Silva, M. J. (2008). Motivações para o ingresso dos idosos em instituições de longa permanência e processos adaptativos: Um estudo de caso. Texto \& Contexto Enfermagem, 17(2), 258-265.

Born, T. (2002). Cuidado ao idoso em instituição. In M. Papaléo Netto (Ed.), Gerontologia: A velhice e o envelhecimento em visão globalizada (pp. 403-414). São Paulo, SP: Atheneu.

Born, T. (2008). O cuidador familiar da pessoa idosa. In T. Born (Ed.), Cuidar melhor e evitar a violência: Manual do cuidador da pessoa idosa (pp. 59-63). Brasília, DF: Secretaria Especial dos Direitos Humanos, Subsecretaria de Promoção e Defesa dos Direitos Humanos.

Brandão, L., Smith, V., Sperb, T. M., \& Parente, M. A. M. P. (2006). Narrativas Intergeracionais. Psicologia: Reflexão e Crítica, 19(1), 98-105.

Braz, A. C., Del Prette, Z. A. P., \& Del Prette, A. (2011). Assertive social skills training for the elderly. Behavioral Psychology, 19(2), 373-387.

Camarano, A. A., \& Kanso, S. (2010). Como as famílias brasileiras estão lidando com os idosos que demandam cuidados e quais as perspectivas futuras? A visão mostrada pelas PNADs. In A. A. Camarano (Ed.), Cuidados de longa duração para a população idosa: Um novo risco social a ser assumido? (pp. 93-122). Rio de Janeiro, RJ: Fundação Instituto de Pesquisa Econômica Aplicada.

Camarano, A. A., \& Kanso, S. (2011). Previdência Social no Brasil: Contornos e horizontes. In G. Biasoto Junior, \& L. A. P. Silva (Orgs.), Políticas Públicas em questão (pp. 27-57). São Paulo, SP: Fundação do Desenvolvimento Administrativo.

Camarano, A. A., \& Mello, J. L. (2010). Cuidados de longa duração no Brasil: $\mathrm{O}$ arcabouço legal e as ações governamentais. In A. A. Camarano (Ed.), Cuidados de longa duração para a população idosa: Um novo risco social a ser assumido? (pp. 67-92). Rio de Janeiro, RJ: Fundação Instituto de Pesquisa Econômica Aplicada.

Carneiro, R. S., Falcone, E., Clark, C., Del Prette, Z. A., \& Del Prette, A. (2007). Qualidade de vida, apoio social e depressão em idosos: Relação com habilidades sociais. Psicologia: Reflexão e Crítica, 20(2), 229-237.

Chaimowicz, F. (1997). A saúde dos idosos brasileiros às vésperas do século XXI: Problemas, projeções e alternativas. Revista de Saúde Pública, 31(2), 184-200.

Christophe, M., \& Camarano, A. A. (2010). Dos asilos às instituições de longa permanência: Uma história de mitos e 
preconceitos. In A. A. Camarano (Ed.), Cuidados de longa duração para a população idosa: Um novo risco social a ser assumido? (pp. 145-162). Rio de Janeiro, RJ: Fundação Instituto de Pesquisa Econômica Aplicada.

Conferência Nacional de Saúde. (1986). Anais da VIII Conferência Nacional de Saúde. Brasília, DF: Autor.

Creswell, J. W. (2010). Revisão da literatura. In J. W. Creswell, Projeto de pesquisa (M. Lopes, Trad., 3. ed., pp. 48-75). Porto Alegre, RS: Artmed.

Davim, R. M. B., Torres, G. V., Dantas, S. M. M., \& Lima, V. M. (2004). Estudo com idosos de instituições asilares no município de Natal/RN: Características socioeconômicas e de saúde. Revista Latino-Americana de Enfermagem, 12(3), 518-524.

Duarte, C. V., \& Santos, M. A. (2004). "E agora... de quem cuidarei?": O cuidar na percepção de idosas institucionalizadas e não institucionalizadas. Psicologia: Ciência e Profissão, 24(1), 2-13.

Ferreira, H. G., \& Barham, E. J. (2011). O envolvimento de idosos em atividades prazerosas: Revisão da literatura sobre instrumento de aferição. Revista Brasileira de Geriatria e Gerontologia, 14, 579-590.

Ferreira, O. G. L., Maciel, S. C., Silva, A. O., Sá, R. C. N., \& Moreira, M. A. S. P. (2010). Significados atribuídos ao envelhecimento: Idoso, velho e idoso ativo. Psico-USF, 15(3), 357-364.

Freire, R. C., Júnior, \& Tavares, M. F. L. (2005). A saúde sob o olhar do idoso institucionalizado: Conhecendo e valorizando sua opinião. Interface: Comunicação, Saúde, Educação, 9(16), 147-158.

Freitas, A. V. S., \& Noronha, C. V. (2010). Idosos em instituições de longa permanência: Falando de cuidado. Interface: Comunicação, Saúde, Educação, 14(33), 359-369.

Garbin, C. A. S., Sumida, D. H., Moimaz, S. A. S., Prado, R. L., \& Silva, M. M. (2010). O envelhecimento na perspectiva do cuidador de idosos. Ciência \& Saúde Coletiva, 15(6), 2941-2948.

Gonçalves, L. G., Vieira, S. T., Siqueira, F. V., \& Hallal, P. C. (2008). Prevalência de quedas em idosos asilados do município de Rio Grande, RS. Revista de Saúde Pública, 42(5), 938-945.

Guerra, A. C. L. C., \& Caldas, C. P. (2010). Dificuldades e recompensas no processo de envelhecimento: A percepção do sujeito idoso. Ciência \& Saúde Coletiva, 15(6), 2931-2940.

Instituto Brasileiro de Geografia e Estatística. (2011). Primeiros resultados definitivos do Censo 2010: População do Brasil é de 190.755.799 pessoas. Recuperado em 12 março, 2012, de WWW.ibge.gov.br/home/estatistica/populacao/censo2010/ defaultt_sinopse.shtm

Lenardt, M. H., HautschWillig, M., Silva, S. C., Shimbo, A. Y., Tallmann, A. E. C., \& Maruo, G. H. (2006). O idoso institucionalizado e a cultura de cuidados profissionais. Cogitare Enfermagem, 11(2), 117-123.

Mahieu, L., \& Gastmans, C. (2012). Sexuality in institutionalized elderly persons: A systematic review of argument-based ethics literature. International Psychogeriatrics, 24(3), 346-357.

Mendes, K. D. S., Silveira, R. C. C. P., \& Galvão, C. M. (2008). Revisão integrativa: Método de pesquisa para a incorporação de evidências na saúde e na Enfermagem. Texto \& Contexto Enfermagem, 17(4), 758-764.

Ministério da Saúde. (2003). Estatuto do idoso. Brasília, DF: Autor.
Morales-Vives, F., \& Vigil-Colet, A. (2012). Are old people so gentle? Functional and dysfunctional impulsivity in the elderly. International Psychogeriatrics, 24(3), 465-471.

Néri, A. L. (2001). O fruto dá sementes: Processos de amadurecimento e envelhecimento. In A. L. Néri (Ed.), Maturidade e velhice: Trajetórias individuais e socioculturais (pp. 11-52). Campinas, SP: Papirus.

Néri, A. L., Yassuda, M. S., Fortes-Burgos, A. C., Mantovani, E P., Arbex, F. S., Torres, S. V. S., ...Guariento, M. E. (2012). Relationships between gender, age, family conditions, physical and mental health, and social isolation of elderly caregivers. International Psychogeriatrics, 24(3), 472-483.

Nunes, V. M. A., Menezes, R. M. P., \& Alchieri, J. C. (2010). Avaliação da qualidade de vida em idosos institucionalizados no município de Natal, Estado do Rio Grande do Norte. Acta Scientiarum, Health Sciences, 32(2), 119-126.

Pavan, F. J., Meneghel, S. N., \& Junges, J. R. (2008). Mulheres idosas enfrentando a institucionalização. Cadernos de Saúde Pública, 24(9), 2187-2190.

Pelegrin, A. K. A. P., Araújo, J. A., Costa, L. C., Cyrillo, R. M. Z., \& Rosset, I. (2008). Idosos de uma instituição de longa permanência de Ribeirão Preto: Níveis de capacidade funcional. Revista Arquivos de Ciências da Saúde, 15(4), 182-188.

Perlini, N. M. O. G., Leite, M. T., \& Furini, A. C. (2007). Em busca de uma instituição para a pessoa idosa morar: Motivos apontados por familiares. Revista da Escola de Enfermagem da USP, 41(2), 229-236.

Pestana, L. C., \& Espírito Santo, F. H. (2008). As engrenagens da saúde na terceira idade: Um estudo com idosos asilados. Revista da Escola de Enfermagem da USP, 42(2), 268-275.

Ramos, L. R. (2003). Fatores determinantes do envelhecimento saudável em idosos residentes em centro urbano: Projeto Epidoso, São Paulo. Cadernos de Saúde Pública, 19(3), 793-798.

Ramos, M. P. (2002). Apoio social e saúde entre idosos. Sociologias, 7, 156-175.

Reis, P. O., \& Ceolim, M. F. (2007). O significado atribuído a "ser idoso" por trabalhadores de instituições de longa permanência. Revista da Escola de Enfermagem da USP, 41(1), 57-64.

Ribeiro, M. T. F., Ferreira, R. C., Magalhães, C. S., Moreira, A. N., \& Ferreira, E. F. (2009). Processo de cuidar nas instituições de longa permanência: Visão dos cuidadores formais de idosos. Revista Brasileira de Enfermagem, 62(6), 870-875.

Rosa, F., Neto, Matsudo, S. M. M., Liposcki, D. B., \& Vieira, G. F. (2005). Estudo dos parâmetros motores de idosos residentes em instituições asilares da grande Florianópolis. Revista Brasileira de Ciência e Movimento, 13(4), 7-15.

Santana, A. J., \& Barboza, J. C., Filho. (2007). Prevalência de sintomas depressivos em idosos institucionalizados na cidade de Salvador. Revista Baiana de Saúde Pública, 31(1), 134-146.

Silberman, C., Souza, C., Wilhems, F., Kipper, L., Wu, V., Diogo, C., ...Chaves, M. (1995). Cognitive deficit and depressive symptoms in a community group of elderly people: A preliminary study. Revista de Saúde Pública, 29(6), 444-450.

Silva, C. A., Carvalho, L. S., Santos, A. C. P. O., \& Menezes, M. R. (2007). Vivendo após a morte de amigos: História oral de idosos. Texto \& Contexto Enfermagem, 16(1), 97-104.

Sommerhalder, C. (2010). Sentido de vida na fase adulta e velhice. Psicologia: Reflexão e Crítica, 23(2), 270-277.

Tier, C. G., Fontana, R. T., \& Soares, N. V. (2004). Refletindo sobre idosos institucionalizados. Revista Brasileira de Enfermagem, 57(3), 332-335. 
Trentini, C. M., Chachamovich, E., Figueiredo, M., Hirakata, V. N., \& Fleck, M. P. A. (2006). A percepção de qualidade de vida do idoso avaliada por si próprio e pelo cuidador. Estudos de Psicologia (Natal), 11(2), 191-197.

United Nations. (2009). World population prospects: The 2008 revision. Retrieved March 12, 2012, from http:/www.un.org/ esa/population/publications/wpp2008/wpp2008_text_tables. pdf

United Nations. (2012). World population prospects: The 2010 revision. Retrieved March 12, 2012, from http://esa.un.org/ wpp/P-WPP/htm/PWPP Population-Age 65Plus.htm

Yamamoto, A., \& Diogo, M. J. D. (2002). Os idosos e as instituições asilares do município de Campinas. Revista Latino-Americana de Enfermagem, 10(5), 660-666. 